Introduction: Metastatic tumors are the most common intraocular malignancies in adults. Anterior segment metastases account for about $7.2-14.1 \%$ of all intraocular metastatic tumors with those to the iris representing $3.6-7.8 \%$ of the cases. Breast and lung are the most frequent primary sites of metastasizing cancer. The aim of this study is to present the case of a 43-year-old patient with a rare small-cell lung carcinoma metastasis to the iris.

Case report: A patient with small-cell lung carcinoma and metastases in the brain who had been treated with chemoand radiotherapy attended an outpatient clinic because of redness of her left eye. Based on the ophthalmological examination, a diagnosis of numerous metastatic tumors to the iris was made and the patient was referred for re-chemotherapy. Complete regression of the iris lesions was observed after 5 months but unfortunately two months later the patient died, due to progression of her systemic disease.

Discussion: Among lung cancers, adenocarcinomas are much more likely to produce distant metastases to the iris than small-cell carcinomas [4]. More than $50 \%$ of patients with small-cell lung carcinoma have metastases in the brain. The survival rate in cases of lung cancer with eye involvement is poor and approximates to 7 months. However, since there is a strong probability of angle involvement and subsequent secondary glaucoma, the early onset of treatment can improve the patient's quality of life during the terminal phase of the disease.

Key words: small-cell lung carcinoma, iris, metastases, regression.

\section{Small-cell lung carcinoma metastasis to the iris - case presentation}

\section{Danuta Nikratowicz, Iwona Rospond-Kubiak, Jarosław Kocięcki}

Department of Ophthalmology, Poznan University of Medical Sciences, Poznan, Poland

Uveal metastases is the most common intraocular malignancy in adults $[1,2]$. According to Duke-Elder, tumor cell emboli can appear in the network of posterior short ciliary arteries and then settle in the choroid. Less frequently they occur in one of the two long posterior or anterior ciliary arteries, which supply the iris [3].

Anterior segment metastases account for $7.2-14.1 \%$ of all intraocular metastatic tumors with those to the iris representing 3.6-7.8\% of the cases [3]. Breast and lung are the most common primary locations of metastasizing cancer. Among lung cancers, adenocarcinomas [4] are much more likely to produce distant metastases to the iris than small-cell carcinomas [5]. However, there are some reports of iris metastases originating from cancers of kidneys, pancreas and endometrium or cervix of the uterus [2].

The aim of this study is to present the case of a 43-year-old patient with a rare presentation of small-cell lung carcinoma metastasis to the iris.

\section{Case report}

A 43-year-old woman, attended the outpatient clinic of the Department of Ophthalmology, Poznan University of Medical Sciences in September 2009, because of the redness and slightly decreased vision in the left eye (LE). She had a history of small-cell lung carcinoma, diagnosed six months previously, and already treated with chemotherapy ( 5 cycles of cisplatin and etoposide) and chest irradiation (total dose of 58 Gy). However, two months after the initial diagnosis, brain metastases appeared. On ophthalmic examination we noted slightly decreased best corrected visual acuity (BCVA) to 0.9 and borderline values of intraocular pressure (IOP) $(22 \mathrm{~mm} \mathrm{Hg})$ of LE. Anterior segment biomicroscopy of the LE revealed a pink, bulky mass on the iris. It had a solid structure with dilated blood vessels on the surface. The tumor involved the lower part of the anterior chamber, reaching up to the pupillary margin, partially covering its aperture. There were also numerous pink, round nodules of different sizes spread over the whole iris (Fig. 1). Right eye appeared normal and no pathology was detected. The patient was referred to the oncologist for re-chemotherapy. She received 7 cycles of chemotherapy (cisplatin and etoposide regimen). On the follow-up, one month later, a regression of the metastatic mass was noted with only a few aggregations of pink tissue on the surface of the iris (Fig. 2). Three months later, at another follow-up, we noted a complete regression of all metastatic nodules with an improvement of BCVA (Fig. 3). Unfortunately, two months later, the general condition of the patient suddenly deteriorated, because of the recurrence of brain metastases. She died due to a disseminated small-cell lung carcinoma 1 year after the initial diagnosis and 7 months after the iris metastases appeared.

\section{Discussion}

Small-cell lung cancer represents $15 \%$ of all lung cancers and, contrary to other histological types, it is characterized by a high index of proliferation, short 


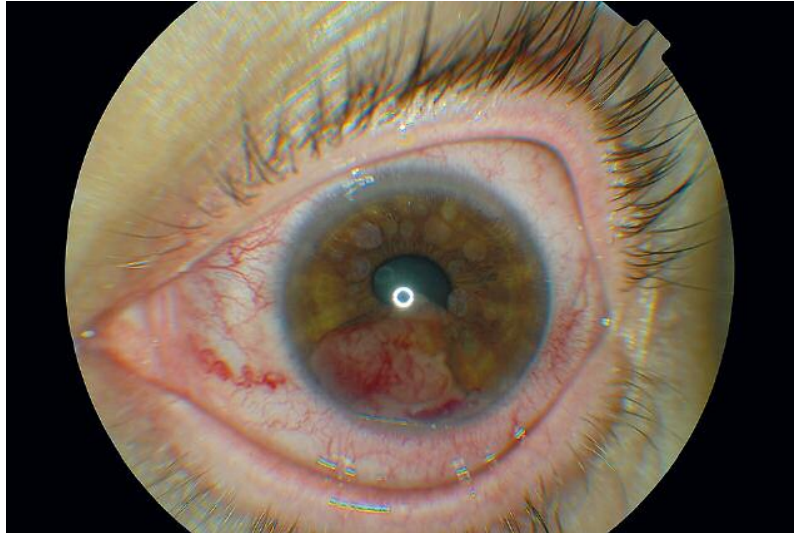

Fig. 1. The anterior segment examination revealed a tumor mass spread over the whole iris

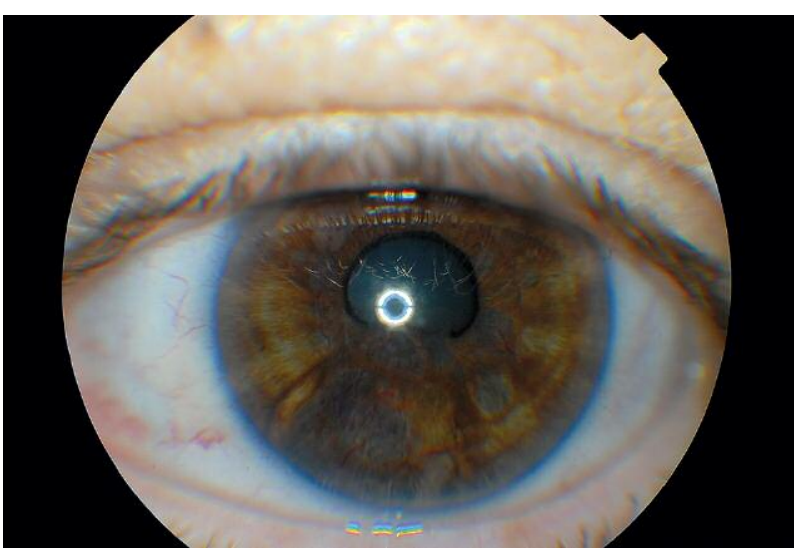

Fig. 2. The partial regression of metastatic mass after 7 cycles of chemotherapy

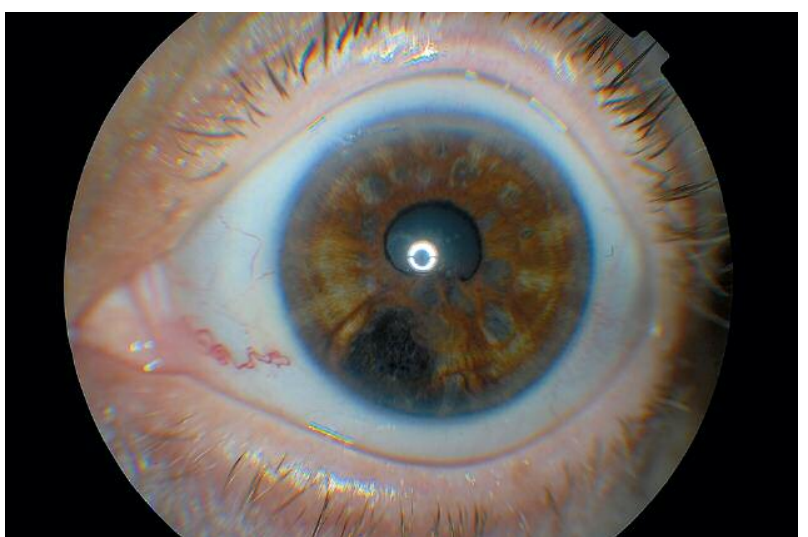

Fig. 3. The complete regression of all metastatic nodules 3 months later

tumor doubling time, a marked tendency to create early bloodrelated metastases, and high sensitivity to chemotherapy and radiotherapy [6]. The 5-year survival rate is only $2.8 \%$ [5]. Smallcell lung cancer can metastasize to the central nervous system [7], liver, bones and bone marrow [5]. Autopsy studies have shown that metastases to the CNS occur in over $50 \%$ of cases [7]. Those to the iris, however, are relatively rare [5], but if they occur, they coexist with CNS metastases in about $44 \%$ of cases [8].

Shields et al. [8] in their study of 40 metastatic iris tumors demonstrated that the most common sites of primary cancer were: breast (40\%), lung (28\%), bronchi carcinoid (8\%), malignant melanoma (8\%), esophagus (2\%), larynx (2\%), prostate $(2 \%)$ and kidney (2\%). All the iris metastes were unilateral, however, in 35\% of cases ipsilateral choroid involvement was noted. There were bilateral choroidal metastases in one case and an orbital involvement in another one [8].

Iris metastases often appear near the irido-corneal angle. This seems to confirm the theory that they are related to the major arterial circle of the iris and spread via the blood stream. Sometimes, with the growing of such a tumor, blood may appear in the anterior chamber with the clinical manifestation mimicking can imitate acute anterior uveitis [3]. The angle involvement will cause secondary glaucoma and painful eye. In our patient intraocular pressure was of borderline values.

Treatment options for iris metastatic tumor include radiotherapy, chemotherapy, local resection (which can be preceded by tumor irradiation), observation or enucleation $[5,8]$. Globe removal should only be advised in the case of a large tumor complicated by refractory secondary glaucoma and pain [1, 5]. Despite many possible treatment options advanced metastatic tumors are always associated with a bad survival prognosis. The mean survival time after a diagnosis of metastases of lung cancer to the iris is 7 months [8], which was also observed in our case. The short survival time seems to limit any benefits of screening programs for metastases in the eye. However, early and effective treatment of detected eye pathology in this group of patients can improve their life quality in the terminal phase of the disease.

The authors declare no conflict of interest.

We thank Prof. Geoffrey Shaw for correction of the English text.

\section{References}

1. Romanowska-Dixon B. Treatment of intraocular metastatic tumors. Klinika Oczna 2003;105: 136-9.

2. Kreusel KM, Wiegel T, Stange M, Bornfeld N, Hinkelbein W, Foerst er MH. Choroidal metastasis in disseminated lung cancer: frequency and risk factors. Am J Ophthalmol 2002; 134: 445-7.

3. Zografos L Tumeurs intraoculaires. Société Française d'Ophthalmologie et Masson. Paris 2002.

4. Okuma Y, Hosomi Y, Kitamura K, Iguchi M. Choroidal metastasis in a patient with small cell lung cancer discovered during treatment with chemotherapy. Int J Clin Oncol 2009; 14: 541-4.

5. Moura LR, Yang YF, Ayres B, Brasil OM, Fernandes BF, Burnier MN Jr. Clinical, histologic, and immunohistochemical evaluation of iris metastases from small cell lung carcinoma. Can J Ophthalmol 2006; 41: 775-7.

6. Krzakowski M, Herman K, Jassem J, Jędrzejczak W. Zalecenia postępowania diagnostyczno-terapeutycznego $w$ nowotworach złośliwych. Polskie Towarzystwo Onkologii Klinicznej. Via Medica, Gdańsk 2009.

7. Roenhorst AWJ, van den Bergh ACM, van Putten JWG, Smit EF. Iris metastasis in small-cell lung carcinoma. J Thorac Oncol 2007; 2: 1128-9.

8. Shields JA, Shields CL, Kiratli H, de Potter P. Metastatic tumors to the iris in 40 patients. Am J Ophthalmol 1995; 119: 422-30. 
Address for correspondence

Danuta Nikratowicz MD

Department of Ophthalmology

Poznan University of Medical Sciences

Długa St. $1 / 2$

61-687 Poznan, Poland

tel. +48618549284

fax +48618549084

e-mail:dnikratowicz@gmail.com

Submitted: $\quad 23.05 .2012$

Accepted: 16.08 .2012 